PONENCIAS

\title{
Hacia un nuevo Código Penal para Chile. Consideraciones sobre los principios en el anteproyecto de Alfredo Etcheberry
}

\author{
Towards a new Penal Code for Chile. Considerations over the principles Alfredo \\ Etcheberry's Criminal Code Project
}

\section{Rocío Lorca Ferreccio \\ Universidad de Chile}

\begin{abstract}
RESUMEN La autora propone entender la cuestión sobre los principios del anteproyecto de Código Penal de Alfredo Etcheberry como una pregunta sobre el origen o el comienzo de los ideales de la codificación penal, en vez de una investigación acerca de los fundamentos axiológicos de las reglas específicas que contiene el proyecto. Buscar los principios mirando hacia atrás, hacia nuestra historia, no debe entenderse en términos conservadores como un retroceso, sino como un volver lógico hacia las condiciones que permiten imaginar al derecho penal como una práctica capaz de habitar el mundo del derecho.
\end{abstract}

PALABRAS CLAVE Principios, castigo, codificación, tragedia griega.

ABSTRACT The author suggests that we understand the problem of the principles in Prof. Em. Etcheberry's Penal Code Project, as an issue about the origins or the beginnings of codification, rather than as an exploration of the values that underlie the specific rules contained in the project. This going back to origins should not be understood in conservative ways as a regression, but rather as a logical return to the conditions that allow us to understand criminal law as a practice that can inhabit the world of the law.

KEYWORDS Principles, punishment, codification, greek tragedy.

El tema que me han propuesto discutir hoy día, en relación al proyecto de Código Penal de Alfredo Etcheberry, se titula «Principios». En derecho estamos acostumbrados a hablar de los principios como aquellas normas que se expresan como orientaciones o compromisos valorativos de los sistemas de reglas y que, por una 
parte, guían la formulación e interpretación de dichas reglas y, por la otra, guían su crítica y reforma.

En el caso del proyecto de Código Penal de Alfredo Etcheberry, las orientaciones o principios que parecen inspirar su articulado son aquellas propias de lo que él mismo denomina el «pensamiento liberal, humanizador y garantista que inspira a nuestro antiguo Código vigente (Etcheberry, 2017: 5)». Un pensamiento que se caracteriza por formular principios como el de reserva legal, el de culpabilidad, proporcionalidad y en muchos casos también el principio de prevención y exclusiva protección de bienes jurídicos. Bajo este paradigma, la selección específica de principios y funciones del derecho penal que el autor realiza dan cuenta de un cierto eclecticismo en el que se expresa un compromiso con la idea del derecho penal como una práctica de responsabilidad individual, pero también un compromiso con una función de prevención y seguridad.

Utilizando la distinción popularizada por el filósofo Isaiah Berlin, este eclecticismo o pluralismo valorativo nos permitiría caracterizar al profesor Etcheberry como un zorro en vez de un erizo (Berlin, 1953).

De acuerdo con un verso del poeta griego Arquíloco, el zorro sabe muchas cosas, mientras que el erizo sabe sólo una, pero una grande (Berlin, 1953; y también Dworkin, 2014: 15). Mientras que las teorías retribucionistas del derecho penal formulan un gran principio de orientación que, de ser correcto, sería capaz de explicar todas las partes del sistema, las teorías que expresan compromiso con los principios liberales de legalidad y culpabilidad, pero que a la vez se dejan orientar por una función de prevención y seguridad, deben rendirle cuenta a varios valores al mismo tiempo: deben, como los zorros, saber muchas cosas, y no una sola.

Los zorros tienen la virtud de poder alojar mayor complejidad y entonces reflejar las tensiones o conflictos entre intereses que se presentan en las sociedades humanas, pero esta pretensión tiene el defecto de que dicha mayor complejidad no siempre es posible de ser alojada en un sistema coherente. Así, será siempre inevitable para un zorro tener que lidiar con la tensión y a veces la inconsistencia que se produce entre los presupuestos de la responsabilidad individual y las necesidades de prevención y seguridad. Frente a estas tensiones, los erizos se presentan con la virtud de la coherencia, con una gran receta para todos los problemas, pero esta coherencia acarrea muchas veces el defecto de la simplificación y, sobre todo, del exceso.

La discusión entre zorros y erizos del derecho penal, sin embargo, es demasiado grande y larga como para seguir sobre ella en esta oportunidad. En cambio, en lo que queda de mi presentación quisiera referirme a la cuestión sobre los principios de este anteproyecto desde una perspectiva algo distinta, donde la idea de principio aparece más como origen que como orientación normativa.

¿Dónde y por qué se origina la intención y la importancia de recodificar a un sistema de justicia penal? Tanto los zorros como los erizos del derecho penal moder- 
no están queriendo un nuevo código y cuando justifican la necesidad de un nuevo código, muchas veces aluden a la importancia de volver a un lugar, a unos ideales, al principio, al comienzo. Este volver no debe entenderse en términos conservadores, como un retroceso, sino como a un volver lógico a las condiciones que permiten imaginar al derecho penal como una práctica capaz de habitar el mundo del derecho, un mundo donde, de acuerdo con el movimiento de la codificación, supuestamente triunfan las virtudes del orden, la racionalidad y la mesura (cf. Grossi, 2010: 39 y ss.).

Entonces, más allá de la evidente necesidad de actualización de nuestro Código y más allá de la importancia de que el Código Penal incorpore cuestiones que han quedado generalmente abandonadas, como la ejecución de las penas, la aspiración central de este proyecto parece ser la necesidad de volver a los ideales de orden, la racionalidad y la mesura, que fueron representados por el movimiento de la codificación del siglo XIX y que difícilmente pueden reconocerse hoy en nuestro derecho positivo (Dubber, 2000: 53-100).

Ya casi nadie discute que la legislación penal está en crisis, precisamente por su desorden, su inconsistencia, su falta de sistematicidad y, sobre todo, por su exceso (cf. Husak, 2013; Dubber, 2000: 53-100). Nuestros códigos penales ya no reflejan políticas criminales, sino que se han constituido en herramientas o armas para la denominada «guerra contra el delito»y, como sabemos, para el derecho es muy difícil regular a la guerra. Esta expansión del derecho penal contemporáneo ha vuelto urgente un retorno a la mesura de la codificación, o a lo que el penalista escocés Antony Duff denomina la parsimonia penal (2010: 293-309).

Estos procesos de codificación y de búsqueda de parsimonia son cíclicos, porque hay tendencias en los objetos de regulación a desregularse y a excederse (Dubber, 2000: 53-100). El derecho penal no sólo no es una excepción a esta tendencia, sino que es posiblemente el área del derecho donde esta resistencia a la mesura se expresa con mayor nitidez. Para ejemplificar esto me gustaría citar una historia de la tragedia griega que relata bajo qué condiciones el derecho penal logra transformarse en una práctica de justicia.

En el relato «Las Euménides» que forma parte de la Orestíada de Esquilo, Orestes viene escapando de la persecución de Las Furias, unos seres horripilantes y rabiosos que quieren vengar la sangre de Clitemnestra, madre de Orestes, a quien él mismo ha dado muerte para vengar el deceso de su padre, el rey Agamenón. Al final de la historia, Orestes llega a Atenas ayudado por Apolo, y allí la diosa Atenea le propone a Las Furias que sometan el ejercicio de su suplicio a la decisión de un tribunal. Si Orestes es hallado culpable Las Furias podrán ejercer su violencia descarnada sobre él, de lo contrario deberán respetar la decisión del tribunal y dejar a Orestes en paz.

Luego de un arduo trabajo de persuasión, Las Furias aceptan el trato propuesto por Atenea. Orestes es declarado inocente y Las Furias son persuadidas de respetar dicha decisión. Con este sometimiento al juicio, Atenea inaugura el Estado de Dere- 
cho y Las Furias deciden quedarse a vivir en Atenas para ayudar en la consolidación de su sistema de justicia. Pero esta decisión produce una transformación en Las Furias, quienes son apaciguadas o «humanizadas,» y pasan de ser unos seres pestilentes, sedientos de venganza, impulsivos y sangrientos, a ser unos seres razonables y a ratos incluso piadosos. De ahí que al final de la historia, Esquilo las rebautiza como Las Euménides, que quiere decir las benevolentes (Allen, 1999: 191 y ss.; Nussbaum, 2016: 1-8).

El relato de Orestes da cuenta de que mediante el sometimiento del impulso de la violencia reactiva, a un proceso de deliberación y persuasión, se origina el castigo como una práctica distinta de la venganza y que es capaz de habitar el mundo del derecho y la justicia, porque puede ser dominada por la razón. Es el carácter deliberado, meditado y mesurado de la violencia de la pena lo que le permite pronunciarse por la boca de la ley y expresarse con la prestancia de la justificación y el merecimiento (Lorca Ferreccio, 2017).

Pero esta posibilidad es escurridiza. El problema del castigo legal, tal como ocurre con Las Euménides, es que sus materias primas, esto es, la violencia de los delitos y las penas, o la naturaleza cruel de las furias, son esencialmente desordenadas e impetuosas: en cualquier momento se pierde el hechizo y Las Euménides volverán a ser Las Furias y el castigo vuelve a ser hostilidad. Ni la persuasión de Atenas ni los procesos modernos de codificación han podido impedir que el monstruo que reside dentro del derecho penal nos lance coletazos de vez en cuando y parezca que está a punto de escaparse.

Los excesos y la desorganización del derecho penal contemporáneo, entonces, no sólo amenazan la vigencia de los derechos individuales de los clientes actuales del sistema, sino que poco a poco van expulsando a la pena estatal del mundo del derecho, transformando nuestras cárceles y tribunales en espacios de exclusión y hostilidad. Por eso que si tiene sentido avanzar hacia un nuevo código penal, debemos entender este esfuerzo, primordialmente, como un esfuerzo por retornar el ejercicio del poder punitivo al ámbito del derecho, y alejarlo del ámbito de la hostilidad.

El derecho penal casi siempre será violento para quien lo sufre, de eso quizás no tenemos escapatoria, pero podemos aspirar a contar con un sistema que no nos de vergüenza, y que pueda aparecer como plausiblemente orientado hacia la obtención de una justicia para humanos. El texto que discutiremos hoy día está decididamente orientado por esta aspiración, por eso quiero aventurar que el verdadero principio sobre el cual se construye el proyecto del profesor Etcheberry es la recuperación del castigo estatal por el derecho penal. Organizar y mesurar al castigo estatal, de un modo tal que éste pueda volver a habitar el mundo del derecho, y no un campo de batalla. 


\section{Referencias}

Allen, Danielle S. (1999). «Democratic Dis-Ease. Of anger and the troubling nature of punishment», En Susan A. Bandes (ed.), The passions of law. Nueva York: New York University Press.

Etcheberry, Alfredo (2017). Proyecto de Código Penal Para Chile. Inédito.

BERLIn, Isaiah (1953). The hedgehod and the fox. An essay on Tolstoy's view of history. Londres: Weidenfeld and Nicolson.

Dubber, Markus (2000). «Penal panopticon: The idea of a modern Penal Code». Buffalo Criminal Law Review, 4 (1).

Duff, Antony (2010). "A criminal law for citizens». Theoretical Criminology, 14 (3).

Dworkin, Ronald (2014). Justicia para erizos. Buenos Aires: Fondo de Cultura Económica.

Grossi, Paolo (2010). A History of European Law. Oxford: Wiley-Blackwell.

Husak, Douglas (2013). Sobrecriminalización. Madrid: Marcial Pons.

Lorca Ferreccio, Rocío (2017). «The deliberated nature of punishment. Roberto Gargarella on democracy and the criminal law». International Journal of Constitutional Law, 15 (2). En prensa.

Nussbaum, Martha (2016). Anger and forgiveness. Oxford: Oxford University Press.

\section{Sobre la autora}

Rocío Lorca Ferreccio es profesora asistente de la Facultad de Derecho de la Universidad de Chile. Su correo electrónico es rlorca@derecho.uchile.cl. 